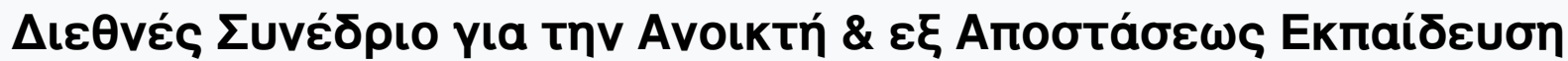

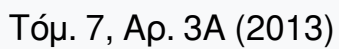

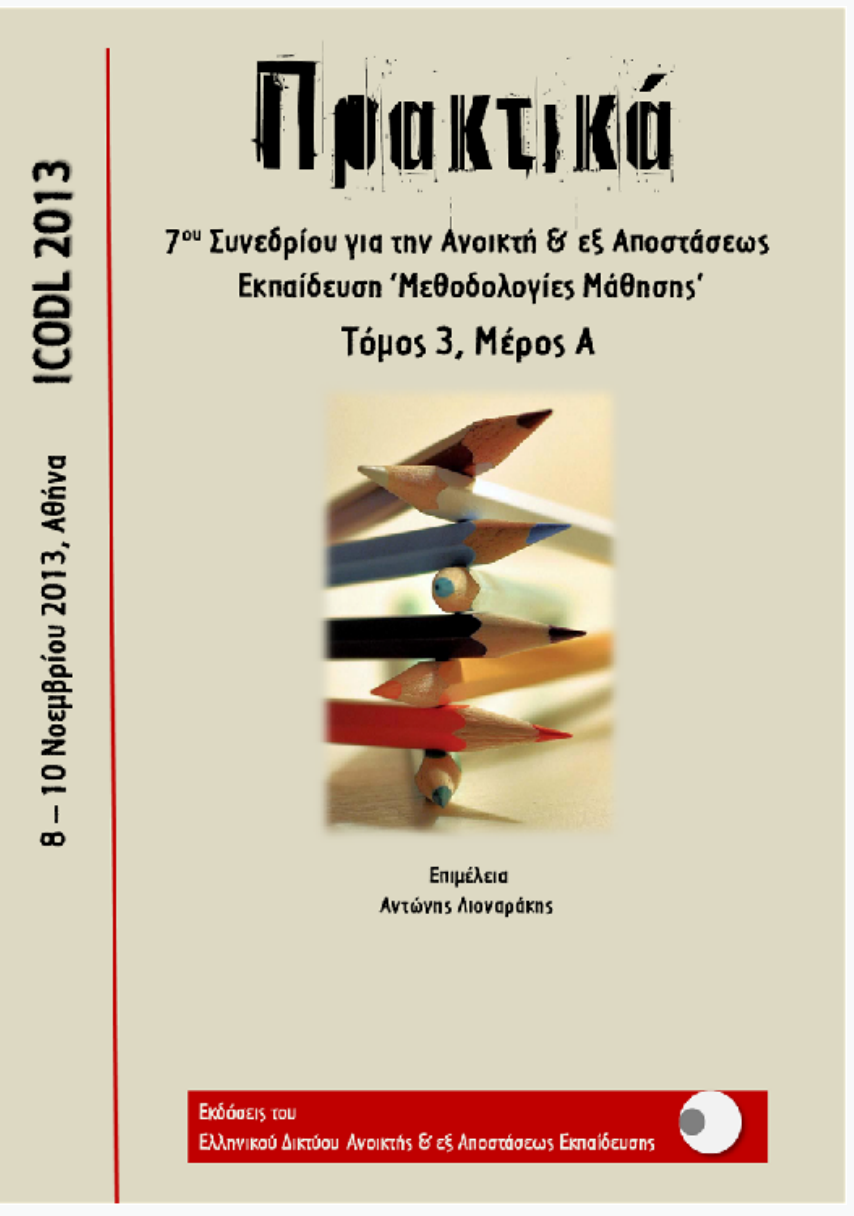

Assessment in eLearning: the case of tutors in Greece based to the CRITON european survey

Achileas Kameas, Adamantia Spanaka, Dimitra Angelopoulou

doi: $10.12681 /$ icodl.604 


\section{Assessment in eLearning: the case of tutors in Greece based to the CRITON european survey}

\section{A

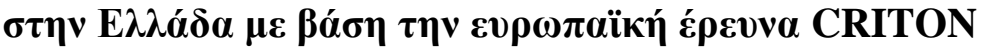

\author{
Achileas Kameas \\ Assistant Professor \\ Hellenic Open University \\ Director of e-CoMeT \\ Laboratory \\ kameas@eap.gr
}

\author{
Adamantia Spanaka \\ Tutor-Counselor in Open and \\ Distance Education, \\ Hellenic Open University \\ Scientific Coordinator in e-CoMeT \\ Laboratory, \\ Hellenic Open University \\ madspa@otenet.gr \\ Dimitra Angelopoulou \\ Scientific Coordinator in e- \\ CoMeT Laboratory, \\ Hellenic Open University \\ dagelopoulou@ecomet.eap.gr
}




\section{$1 \quad$ Assessment in eLearning environments}

E-Learning can be considered to be highly related to learning and teaching (Gruttmann \& Usenev, 2011; Raith, 2009). Therefore, pedagogy and didactic are important aspects for all facets of eLearning (Spector \& Ohrazda, 2003), expanding from the creation of the courseware and application of an eLearning system to the evaluation of the learning progress. In particular, didactic has a great impact on designing and mediating learning content (e.g. see Gunawardena \& McIsaac, 2003). Considering the traditional teaching process, the teacher has to decide which competencies have to be mastered by the students, to which point they extent and how the result of the learning process should be measured. Such considerations are usually realised by determining learning objectives and assessment methods for a course.

With respect to Mödritscher \& Sindler (2005), applying certain didactical principles can be challenging in the eLearning situation. In particular, the assessment takes an important place during the development of any of e- learning course. It includes a variety of activities such as testing, problem solving, developing collaborative or individual projects development, participating in discussions etc. The object of assessment in the educational process is not only the knowledge. As IDS (2002) points out, the necessity of using the appropriate assessment which should be performed not only to grade students, but also to measure the learning process.

The assessment area is enlarged toward the skills and competences. According to Mödritscher et al. (2004) the competence is a mastering of knowledge and skills at level that is sufficient for their application for doing concrete work. Howard Gardner's Multiple Intelligences Theory (1983) describes three main classes of competencies:

(1) knowledge seen as a kind of mental model about parts of the real world,

(2) skills related to the capacity of applying and using acquired knowledge, and

(3) attitudes dealing with social or affective aspects.

In praxis, competency is supposed to be related to more than one of these classes. In most cases a strong focus on one class can be recognised, but adequately mixed competencies can also be found. That's why the assessment method has a great impact on the students' learning behavior (Lombardi, 2007). And this is the reason, the eLearning assessor should keep in mind that when eLearning is implemented, students should be led to the desirable direction as they are taught in the classroom. Both classroom teaching and eLearning should be comparable and yield significant impacts to students' progress.

So, the approach of using different assessment methods should be applied in eLearning environments. The assessment methods are based on relevant assessment activities. These activities could be aggregated in an assessment unit and they could be used to measure student's achievements and driving of learning path in a concrete e- learning course, module, chapter, lesson etc. Teachers have to consider which type of question they use for assessment depending on the level of learning objectives, size of the class, reliability in grading, prevention of cheating, exam construction and grading time, and several other criteria.

Thus, three critical questions arise when planning and evaluating a course: What competencies should be mediated to the students? To which extend should these competencies be mastered? And how can the results of the learning process be measured after having finished the course?

Based on all these, different assessment methods used in eLearning environments around Europe are in the focus of this study.

There will also be an answer to questions like:

1. What are the basic types of assessments available and which are the most widely used in the case of Greek tutors in eLearning environment?

3. What are some different methods of assessment in eLearning environment?

5. What are some methods to find the right mix of assessments for an online course or learning sequence?

6. How can feedback influence student achievement in eLearning?

\section{From Assessment to e-Assessment}

Technology can add value to assessment practice in a multitude of ways. The term e- 
assessment is a broadly-based one, covering a range of activities in which digital technologies are used in assessment. Such activities include the designing and delivery of assessments, marking - by computers, or humans assisted by scanners and online tools - and all processes of reporting, storing and transferring of data associated with public and internal assessments.

If used with skill and imagination, e-assessment can increase the range of what is tested. It can provide evidence of both cognitive and skills-based achievements in ways that are durable and transferable. It can enhance the validity of assessment systems and encourage deeper learning.

e-Assessment, in fact, is much more than just an alternative way of doing what we already do. A growing body of evidence indicates that well-designed and well-deployed diagnostic and formative assessments can foster more effective learning for a wider diversity of learners. Assessment is perhaps the best way of identifying the support needs of learners and can instill a desire to further progress if linked to appropriate resources, good quality, timely feedback, and to challenging but stimulating ways of demonstrating understanding and skills. Effective use of technology can make significant contributions here.

Additionally, e-Assessment can support personalisation. Any time, anywhere assessments benefit learners for whom a traditional assessment regime presents difficulties due to distance, disability, illness, or work commitments. On-demand summative assessments, when available, increase participation in learning by enabling learners to advance at a pace and in a way appropriate to them.

Furthermore, some forms of e-assessment may be used at each of the three stages at which a learner's attainment and progress come under review:

- Diagnostic - assessment of a learner's knowledge and skills at the outset of a course.

- Formative - assessment that provides developmental feedback to a learner on his or her current understanding and skills. Formative assessment can also be described as 'assessment for learning' since an assessment that is entered into voluntarily, and on which no final qualification depends, can prompt learners to adjust their own performance.

- Summative - the final assessment of a learner's achievement, usually leading to a formal qualification or certification of a skill. Summative assessment is also referred to as assessment of learning.

\section{General information about the survey}

In CRITON survey, Workpackage 2 (WP 2) studies and surveies the different assessment methods used in eLearning environments across Europe, in order to define the most widely used assessment practices, which can provide accurate measure of learners performance in eLearning. In this paper, the main results of the field research in the case of tutors in Greece are been presented. 60 questionnaires have been selected at the period of May 2013 until June of 2013. Statistical analysis of the data includes descriptive statistics, crosstabs and chi-square test of independence to determine whether there is a relationship between variables and was performed in SPSS v.20.

\section{$4 \quad$ Research Results}

In the research 60 tutors have taken part. Most of them are tutors in Open and Distance Learning University (33\%) or in conventional University $(25 \%)$ as you can see on table 1. 


\begin{tabular}{|l|l|l|}
\hline & $\begin{array}{l}\text { Total } \\
\text { Number }\end{array}$ & $\begin{array}{l}\text { Percentage } \\
(\%)\end{array}$ \\
\hline Primary Education & 4 & 7 \\
\hline Secondary Education & 6 & 10 \\
\hline VET & 8 & 13 \\
\hline Conventional University & 15 & 25 \\
\hline $\begin{array}{l}\text { Open and Distance Learning } \\
\text { University }\end{array}$ & 20 & 33 \\
\hline Adult Education & 7 & 12 \\
\hline
\end{tabular}

Table 1: Participants in the survey

As about what tutors consider most important in a assessment method in an eLearning environment, and what they believe that should be supported by a method like that, results show that all the tutors $(100 \%)$ consider that assessment method should give emphasis on eLearning and then rethinking of curriculum (93\%). On the other hand, most tutors -regardless the level of education they work for (based on $\mathrm{X}^{2}$ test)considers that an assessment method in eLearning environment supports Higher order thinking (78\%), while a few less believes that an assessment method supports social skills and group work (61-63\%).

Tutors in order to enhance the learning experience through assessment, they take into account mainly the subjects objectives, but also the needs, characteristics and situation of the learners. Their time and effort to design tasks have in mind the $2 / 3$ of tutors, according to statistical test $\mathrm{X}^{2}$. There is also a comment about taking concern the learner's level of computer literacy, which could be taken for granted in the case of typical learning, but not in the case of adult education.

As about the selection of the type of assessment format, the vast majority of tutors $(97 \%)$ depends it on learning objectives and on grading time $(73 \%)$, on prevention of cheating student $(66 \%)$ or on the size of the class $(58 \%)$.

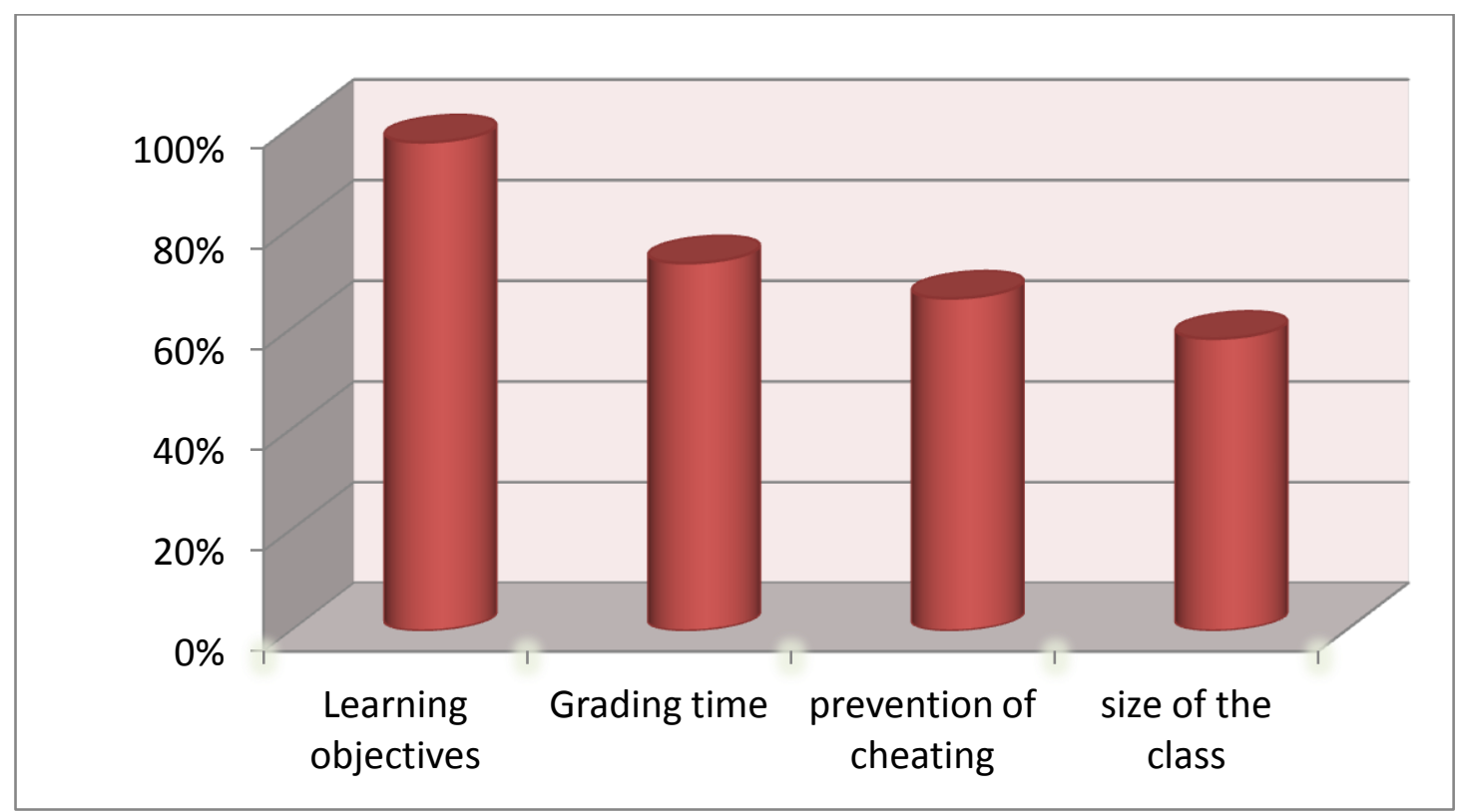

Graph 1: Selection of assessment format

In Greece, the $X^{2}$ test of statistical significance, shows a differentiation in the level of agreement of a tutor according to his teaching grade position to the hypothesis that the assessment method depends on the learning goals. The higher the tutors teaching 
grade, the higher the percentage of those who strongly agree that the selection of the type of assessment format depends on learning objectives.

The predominant assessment format in eLearning environment is Multiple Choice Question (MCQ) (59\%), while the next format is the Short answer question type. All the other assessment formats gather very low preference percentage, while $\mathrm{X}^{2}$ test of statistical significance shows that there is no relevance with tutor's teaching grade.

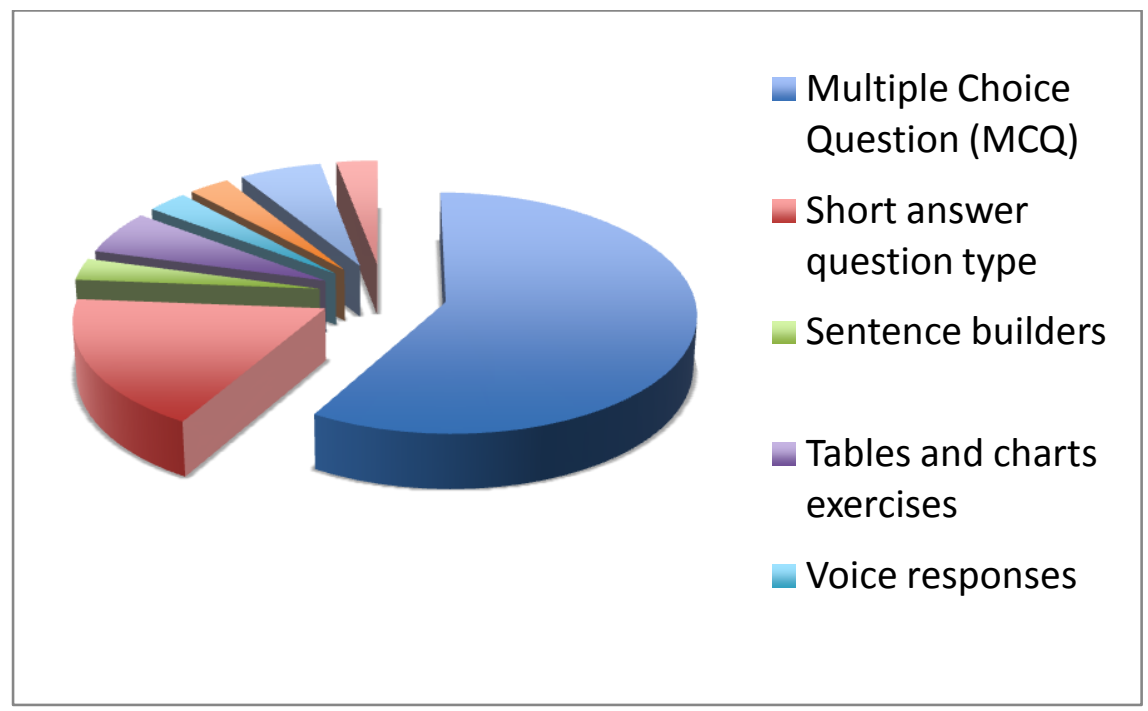

Graph 2: The predominent assessment format

Other predominant e-assessment format that some tutors use are e-portfolio, essay and written assignments.

By eliminating the preferable type of assessment to 4, results doesn't change significantly, but increases the percentage of tutors who like to use tables and charts exercises for assessment. Additionally, some tutors comment that they prefer to construct other types of assessment, as e-portfolio (in primary education), assignments (conventional university), case studies, Wiki assignments and participation assessment in the lesson's forum.

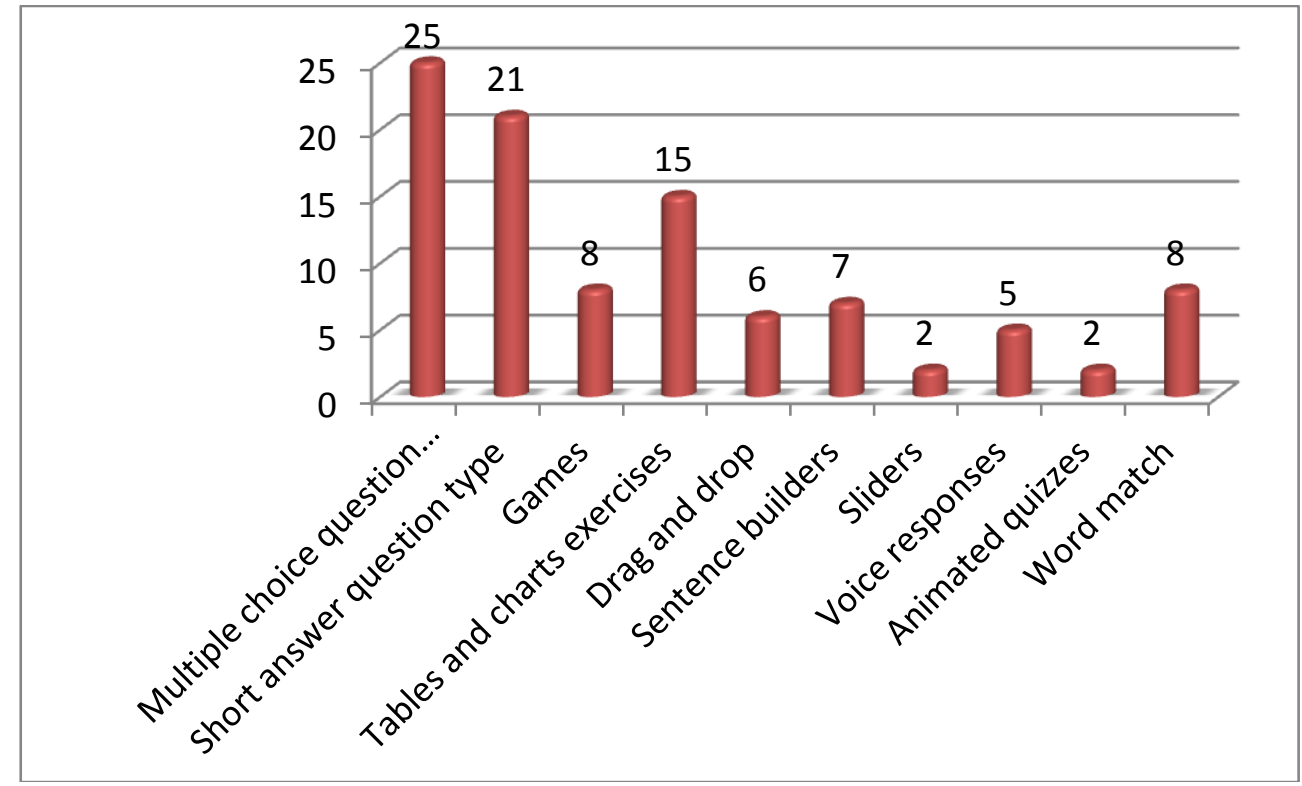

Graph 3: Preference classification of assessment format in eLearning Selection of the 4 most preferable assessment formats 
Tutors explain why they use those types of assessment and how they think they could be used more effectively:

- MCQ is a more functional format of assessment and suits better for some learners (for example, working men). Additional, MCQs' may be more focused and objective as well in a elearning environment, and they are familiar to adult learners. Tutors consider that they promote active participation in education and provide better material comprehention.

- Short answer question type develop critical thought, demand clarity in the answer and test the learner's expression ability and assissts him in developing a personal writting style. It is also a type which prevents cheating.

- Games are more attractive, more interactive and more flexible way of assessment, while experience and practice incormporation are achieved effectively in a way which activate multiple skills.

- Tables and charts exercises help for better data visualization.

Totally, a lot of tutors select to use many different formats of assessment, because they consider that -by this manner- final results are more safe, objective and reliable, while assessment can be more interested if it uses games.

The 4 most preferrable assessment formats classification, shows that tutor's selection reflects their theoretical aspects, as well as their experiences in education. So, they choose the assessment format according the age group of the learners, as well as their potential level in order to better fit them in the eLearning training character. So, they select an assessment type in order to contribute in the comprehension of the study material, which is rather "dens" and extends on time and place. In that way, learners are assisted in studing, while, on the other hand, tutor can better evaluate their final results.

Tutors believe that the combination of various assessment formats gives rise to more effective and objective assessment, with higher learner's participation. So assessment can be less formulaic and perhaps less stressful. As a bonus they cover all assessment formats, they activate thought and test the total of knowledge.

Suggestions for upgrating these assessment formats are the following:

1. The creation of a topic bank, as a product of a team work

2. The decrease of the size with simultanious increase of the number of assignments

3. The use of assessment formats through inteligent interactive applications for ipad, iphone.

An indirect assessment mode of the learner's study process is also measuring his contribution in forum, used by the vast magority of tutors (76\%), as shown on Table 2 and 3.

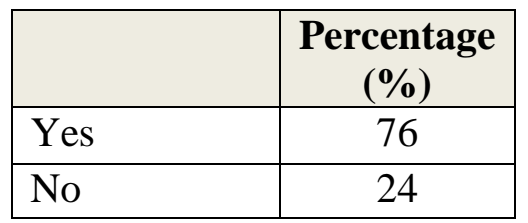

Table 2: Measurement of learner's contribution in an online forum 


\begin{tabular}{|l|l|}
\hline & $\begin{array}{l}\text { Percentage } \\
(\boldsymbol{\%})\end{array}$ \\
\hline Formal assessment & 31 \\
\hline Formative and supplementary purposes & 69 \\
\hline
\end{tabular}

Table 3: Measurement usage of learner's contribution in an online forum

Results are more divided for the use of e-portfolio, as evidence of work undertaken, while its use is divided between formal assessment and other formative and supplementary purposes.

\section{Conclusions}

According to literature, assessment is an ongoing process that involves planning, discussion, consensus building, reflection, measuring, analyzing and improving based on data and artifacts gathered about a learning objective. Any assessment is linked to critical questions, such as:

- Why do we measure?

- What we are measuring?

- How do we measure it?

- How much do we need to measure?

- When do we measure it?

With respect to the tutor's use of different assessment methods in eLearning environment, the results show:

- Diagnostic assessment, which means assessment of learner's knowledge and skills at the outset of a course, seldom conduct half of the tutors, while only the $13 \%$ perform such method of assessment. This is a very significal result, especially for adult education. This is an important part of teaching management and should be taken in mind in designing the learning material.

- Formative assessment, which provides gradual feedback to learner about his or her progress during lessons. It is applied (usually or always) by about the $60 \%$ of tutors.

- Summative assessment, after the lessons have been concluded. It is preferred by the vast majority of tutors, while only the $8 \%$ don't ever use this kind of assessment.

- It is interesting that almost one to five tutors contucts always peer-assessment, and that only $36 \%$ of tutors usually use peer-assessment.

There is an interesting interellation between tutors choices to use summative assessment and peer assessment. The less a tutor use peer assessment, accordingly the less he uses and summative assessment. So, the $67 \%$ of those who never perform peer-assessment, do not go on to final assessment. This could be a case for further research.

\section{References}

Gruttmann, S. \& Usener, C. (2011). Prüfen mit Computer und Internet - Didaktik, Methodik und Organisation von E-Assessment. University of Graz

Gunawardena, C.N. \& McIsaac, M.S. (2003). Distance education. In: Educational Technology Research and Development, pp. 355-396.

IDS (2002). Instruction at FSU: A Guide to Teaching and Learning Practices. Instructional

Development Services, Florida State University.

Lombardi, M. (2007). Authentic Learning for the $21^{\text {st }}$ Century: An Overview. ELI Paper. EDUCAUSE. 
$7^{\text {th }}$ International Conference in Open \& Distance Learning - November 2013, Athens, Greece - PROCEEDINGS

Mödritscher, F., García-Barrios, V.M., \& Gütl, C. (2004). The Past, the Present and the Future of adaptive E- Learning: An Approach within the Scope of the Research Project AdeLE. In: Proceedings of the International Conference on Interactive Computer Aided Learning (ICL2004), Villach, Austria.

Raith, A. (2004). E-Testing im österreichischen Hochschulbereich - eine Chance? Donau-Universität Krems.

Spector, J.M. \& Ohrazda, C. (2003). Automating instructional design: Approaches and limitations. In: Educational Technology Research and Development, pp. 685-700.

CRITON - 530945-LLP-1-2012-1-GR-KA3-KA3MP

This project has been funded with support from the European Commission. 